Journal of Research in Interprofessional

Practice and

Education

Vol. 3.1

March, 2013
Journal of Research in Interprofessional Practice and Education (JRIPE)

Vol. 3.1

(C) 2013

Corresponding author: Shelly Doucet. Email: 'śdoucet@unb.ca.'

\section{Patients' Messages as Educators in an Interprofessional Health Education Program}

\author{
Shelley Doucet, BN, MScN, PhD; Heidi Lauckner, OT Reg (NS), PhD; \\ \& Sandy Wells, BPHE, MSc
}

\begin{abstract}
Background: Patients have traditionally played a passive role in health professional education. Health Mentors Programs are new, innovative interprofessional education initiatives that involve "health mentors" (volunteer community patient educators), who share their experiences navigating the healthcare system with an interprofessional team of four health professional students. The purpose of this research was to explore what motivated the patient educators to participate in the Dalhousie Health Mentors Program and what messages they wanted to instill in health professional students.

Methods: Data were collected through seven semi-structured focus groups $(N=29)$ and one individual interview $(N=1)$, which were recorded and transcribed verbatim. Qualitative inductive thematic analysis was used to identify key themes.

Findings: Our study demonstrated that patients want to play an active role in educating health professional students with the hope of improving the healthcare system. The mentors wanted to convey to the students the importance of interprofessional collaboration, understanding patients are people first, listening to patients, and understanding the visible and invisible impacts of living with chronic conditions.

Conclusions: If we expect our students to become competent in providing interprofessional, patient-centred care, it is important that we provide opportunities for patients to be actively involved in health professional education, as they have important messages that cannot be taught from a textbook.

Keywords: Patient educators; Interprofessional education; Health professional education; Messages; Health Mentors Program
\end{abstract}

\section{Introduction}

Although patients have been involved in health education for many years, they have traditionally played a passive role, often as a demonstration or illustration of what the instructor is teaching [1]. The active involvement of patients as educators is increasingly being recognized as a strategy to teach patient-centred and interprofessional care [2]. In certain countries, such as the UK, patient involvement in health professional education is mandated by the government.

The growing trend toward more active patient involvement in health professional education, while promising, is not currently well researched. Most investigations of patient involvement in health education have focused on the experiences and learning outcomes of the students, while research exploring the role of patients as educators, particularly in interprofessional education initiatives, is limited. To date, researchers interested in the patient-as-educator role have examined patients' satisfaction in their role as an educator, with little attention placed on what patients think they actively contribute to the teaching/learning relationship [1]. The current article 
93

Patients' Messages as Educators

Doucet, Lauckner, \& Wells

Journal of Research in Interprofessional Practice and Education

Vol. 3.1

March, 2013 addresses this gap by reporting the results of our investigation of patient educator experiences in the Dalhousie Health Mentors Program (HMP), which is an interprofessional health education initiative that includes patients as educators/mentors at its centre. The purpose of this research was to explore what motivated the patient educators to participate in the Dalhousie HMP and what messages they wanted to instill in health professional students when participating as a health mentor.

\section{Context}

Health Programs are innovative interprofessional education initiatives that introduce students to collaboration in healthcare through interprofessional student teams that work on projects centred on their assigned health mentor, the volunteer patient educator. The first HMP was introduced at Thomas Jefferson University in Pennsylvania in 2007 [3]. Variations of the Jefferson model have been piloted throughout Canada and the United States. In the fall of 2010, an HMP was introduced at Dalhousie University in Nova Scotia, Canada. The Dalhousie HMP involves approximately 600 health professional students, most of whom are enrolled in one of 17 programs from three Dalhousie faculties (Medicine, Dentistry, and Health Professions). Dalhousie also offers a distributed medical (MD) education program in New Brunswick, where Dalhousie has partnered with the Department of Nursing \& Health Sciences at the University of New Brunswick to run the HMP at the distributed site. Therefore, the Dalhousie HMP includes a total of 18 participating programs, runs concurrently in two provinces, and involves intra- and interuniversity partnerships, as well as volunteer patient involvement.

Students from participating programs are grouped into interprofessional teams of four and are assigned to a health mentor. Health mentors involved in the Dalhousie HMP are community volunteers with a chronic condition and/or disability who are willing to share their experience of living with their condition and navigating the healthcare system. They were recruited from the community through various means, in particular, through networking with condition-specific support groups and networks. In the inaugural Dalhousie HMP (2010-2011), 151 health mentors participated. The interprofessional student teams met with their assigned health mentor three or four times during the academic year, with the aim of learning about patient/client-centred practice, team functioning, and chronic conditions and disabilities. The students were required to complete several assignments designed to foster collaboration and patient-centred practice. Each team was also assigned to a faculty supervisor, whose main roles were to support student teams through the process of collaboration, to provide feedback on assignments, and to evaluate learning outcomes. The assignments guided the student teams' encounters with the health mentors, and the completion of each assignment was a product of the student teams' collaboration and their engagement with the health mentors.

While the student teams had the benefit of a faculty supervisor, the health mentors were supported through the program by the HMP co-ordinator. After initial recruitment, the health mentors attended a 1.5-hour orientation in September 2010, prior to the commencement of the program. The orientation was focused on the 
Patients' Messages as Educators

Doucet, Lauckner, \& Wells

Journal of Research in Interprofessional Practice and Education

Vol. 3.1

March, 2013

\section{Journal of Research in Interprofessional Practice and Education}

Dalhousie HMP objectives and the roles of participants. The health mentors were not remunerated for their participation in the program; however, they were given the option of having the costs of their travel covered for attending the orientation and student team visits. Using Towle and colleagues' [4] taxonomy for the spectrum of patient involvement in the learning encounter, the patient educators in our program are on level three: The patient shares his or her experience with students within a faculty-directed curriculum. At this level, faculty members plan the encounter. The patients are invited to share their experiences with the students, and they determine their own comfort level in terms of what is shared. They are not involved in curriculum development, evaluation of the students, or input at the organizational level.

\section{Methods}

A qualitative descriptive design was used to gain an in-depth understanding of what motivated health mentors to participate in the Dalhousie HMP and what messages they wanted to share with health professional students. Ethics approval was obtained and, following an explanation of the study, all participants provided written informed consent.

\section{Setting and sample}

The population of interest was the 151 health mentors involved in the pilot year of the Dalhousie HMP. All mentors were eligible to participate. Of the 151 health mentors, the first 30 who were interested and available participated in the study. To achieve an adequate sample, the exact number of participants was determined through data saturation and repetitive patterns [5]. All interviews took place in a private room at the University, either at the Nova Scotia or the New Brunswick campus.

\section{Data collection}

Data were collected through seven semi-structured focus groups $(N=29)$ and one individual interview $(N=1)$ that took place between three and four months after the 2010-2011 HMP was completed. Focus groups were used as a means to deepen the richness of the data gathered because participants could build upon, clarify, or contradict the experiences of others in the group [5]. The focus groups and individual interview took place in person and were each facilitated by two experienced researchers. They ranged in duration from 60 to 120 minutes, with most lasting approximately one hour. With the participants' permission, all interviews were audio-recorded and transcribed verbatim.

\section{Data analysis}

The data were analyzed using inductive thematic analysis, which is a research method for identifying, analyzing, and reporting themes within qualitative data [6]. Thematic analysis is a useful research tool for obtaining a rich, detailed, and complex account of data. The analysis was guided by six phases: 1) establish familiarity with the data, 2) generate initial codes, 3) search for themes, 4) review themes, 5) define and name themes, and 6) disseminate the findings [6]. 
JRIPE

95

Patients' Messages as Educators

Doucet, Lauckner, \& Wells
Journal of Research in Interprofessional Practice and Education

Vol. 3.1

March, 2013
Journal of Research in Interprofessional Practice and Education

To ensure the transcripts were analyzed with rigor, the three study investigators, who are experienced qualitative researchers, reviewed and coded the transcript of the first focus group to generate preliminary codes and working definitions. The first two authors then applied the generated codes to subsequent transcripts using colour coding in a word processing program. Differences or uncertainties in coding were noted and discussed between the researchers to arrive at consensus. Additional codes were developed and discussed as required. The text under each code was then reviewed to identify key themes. The research team discussed the emerging themes to ensure clarity and robustness. Themes with less supporting data were integrated into more robust themes. The relationships between themes were also examined to further deepen the analysis.

\section{Results}

Table 1 provides the demographic information of the 30 participants. The average age of the health mentors was $55(S D=11.17)$, with a range of 28 to 81 years. There was diversity in mentor health conditions, including diabetes, chronic pain, multiple sclerosis, cancer, stroke, and various rare conditions. Many of the mentors had more than one chronic condition or disability.

While a few of the participants identified an immediate goal for participating in the HMP, such as accessing a family doctor or inspiring students to learn more about their rare condition, the majority reported having specific lessons, or messages, which resulted from their experiences with the healthcare system, that they wished to convey to developing healthcare practitioners. The role of "educator" (rather than "simulated patient" or "volunteer patient") created an avenue not otherwise available within the healthcare system for the mentors to provide feedback and improve the provision of care for chronic conditions. This feed-
Table 1: Socio-demographic characteristics of the health mentors $(\boldsymbol{N}=30)$

\begin{tabular}{|c|c|c|}
\hline Characteristic & $N$ & $\%$ \\
\hline \multicolumn{3}{|l|}{ Gender } \\
\hline Female & 18 & $60.0 \%$ \\
\hline Male & 12 & $40.0 \%$ \\
\hline \multicolumn{3}{|l|}{ Marital status } \\
\hline Married & 13 & $43.3 \%$ \\
\hline Common-law & 2 & $6.7 \%$ \\
\hline Divorced / separated & 8 & $26.7 \%$ \\
\hline Single & 6 & $20.0 \%$ \\
\hline Widow & 1 & $3.3 \%$ \\
\hline \multicolumn{3}{|l|}{ Self-identified ethnicity } \\
\hline Canadian & 20 & $66.7 \%$ \\
\hline Irish & 3 & $10.0 \%$ \\
\hline Dutch & 2 & $6.7 \%$ \\
\hline Other & 5 & $16.7 \%$ \\
\hline \multicolumn{3}{|l|}{ Employment status } \\
\hline Full-time & 5 & $16.7 \%$ \\
\hline Part-time & 2 & $6.7 \%$ \\
\hline Retired & 7 & $23.3 \%$ \\
\hline Homemaker & 2 & $6.7 \%$ \\
\hline Unemployed & 1 & $3.3 \%$ \\
\hline Can't work due to disability & 13 & $43.3 \%$ \\
\hline \multicolumn{3}{|l|}{ Highest level of education } \\
\hline Postgraduate education & 8 & $26.7 \%$ \\
\hline University/college & 9 & $30.0 \%$ \\
\hline Technical school/college & 6 & $20.0 \%$ \\
\hline Partial university/college & 2 & $6.7 \%$ \\
\hline High school & 3 & $10.0 \%$ \\
\hline Partial high school & 2 & $6.7 \%$ \\
\hline \multicolumn{3}{|l|}{ First language } \\
\hline English & 28 & $93.3 \%$ \\
\hline French & 1 & $3.3 \%$ \\
\hline German/Dutch & 1 & $3.3 \%$ \\
\hline
\end{tabular}


JRIPE

96

Patients' Messages as Educators

Doucet, Lauckner, \& Wells

Journal of Research in Interprofessional Practice and Education

Vol. 3.1

March, 2013 back loop was seen as central to the health mentors' perceived role. As one mentor stated: "If we want the system to change, it has to start with us."

Four key messages emerged that the health mentors wanted to convey to the health professional students in order to promote this change in the healthcare system. These four messages included the importance of: 1) health professional collaboration, with patients at the centre, 2) recognizing patients are people first, 3) understanding the visible and invisible impacts of chronic conditions, and 4) putting the pen down and listening to the person. Each of these messages is described below, followed by the mentors' suggestions of how best to convey these messages (Table 2).

\section{Table 2: Mentors' messages and factors that contributed to messages being conveyed}

\begin{tabular}{l} 
Mentors' messages \\
\hline $\begin{array}{l}\text { 1. Health professional collaboration, with patients at the centre } \\
\text { 2. Recognizing patients are people first } \\
\text { 3. Putting the pen down and listening to the person } \\
\text { 4. Understanding the visible and invisible impacts of chronic conditions }\end{array}$ \\
\hline Factors that contributed to mentors' messages being conveyed \\
\hline $\begin{array}{l}\text { 1. Mentor honesty and openness } \\
\text { 2. Student questioning/listening }\end{array}$
\end{tabular}

\section{Mentors' messages}

\section{Health professional collaboration, with patients at the centre}

The health mentors wanted to instill in the students the need for collaboration and co-operation among disciplines. Many of the mentors had a complicated health history, and they identified that throughout their encounters with the healthcare system, their healthcare team rarely communicated with each other and did not practice collaboratively. The mentors emphasized the importance of students understanding the value of interprofessional collaboration early in their careers. As one mentor explained: "If the students don't sit down in a room together and learn how to ask questions and share experiences ... when they are 21 or whatever ... when are they going to learn it? Certainly not when they are 50."

The health mentors also wanted the students to recognize the need for patients to be at the centre of the interprofessional team. For instance, one mentor stated: "the relationship with healthcare providers should be more interactive, and patients should have more of a say in their own care. And the way they're treated by the medical system, it should be more of a team effort." Many of the mentors also wanted the students to recognize that patients have to take responsibility for their wellbeing and not overly rely on the healthcare team.

\section{Recognizing patients are people first}

All of the health mentors had messages regarding the need for a holistic approach in the delivery of healthcare. A message that came across consistently was that patients are people first, and that, as one mentor described: "There's a real person 
Patients' Messages as Educators

Doucet, Lauckner, \& Wells

Journal of Research in Interprofessional Practice and Education

Vol. 3.1

March, 2013

\section{Journal of Research in Interprofessional Practice and Education}

behind the diagnosis." Another mentor illustrated this message by saying: "as much as we are called patients, we are actually people and not primarily patients. We're just folks like you and like everybody else that's had some sort of misfortune health wise." One way some mentors reinforced this point was to invite their student team to visit them in their home. The health mentors were free to meet with students in any mutually agreed upon location; however, some mentors felt that having the students come to their home was critical to understanding that they are a person with many facets beyond their diagnosis. As one mentor stated: "To me, it was really important that they see all the different adaptations [made to accommodate the health condition(s)] and that I am a person, I do have a life, I do have a family."

The health mentors also wanted to send a message to the students that learning solely from books is not sufficient to fully understand the complexity of being a person living with a chronic condition. As one mentor explained:

I think the information that they can gather through books is more scientific, fact based, but it doesn't describe much of anything of how those symptoms actually affect a person. [In the Health Mentors Program] you get the real value of how their condition actually affects them on a daily basis and you don't get that in a book.

\section{Putting the pen down and listening to the person}

In addition to being treated as a person, the health mentors also wanted the students to understand the importance of really listening to patients when providing care. For example, one mentor stated:

Healthcare professionals ... need to be better listeners and not pigeonhole people. Not just say oh, your blood pressure is up, I am going to write you a prescription-you're out the door now without looking at the whole thing. They need to listen to people.

Another mentor confirmed this message and said: "Put the pen down, get your nose out of the clipboard and listen to the person."

It was also important to the mentors that the students learn the importance of using active listening skills. For example, one mentor stated the need for health professionals "to not just listen to what we actually say but also to listen in a way that draws out of us the things that you maybe didn't think were important." Finally, the mentors also wanted the students to recognize the need for health professionals to listen to one another.

\section{Understanding the visible and invisible impacts of chronic conditions}

The final message the health mentors wanted to convey was for the students to see firsthand the lasting impact of having a chronic condition. To illustrate this message, one mentor stated: "It is not something that you can put a bandage on and it is fixed." Many of the mentors assumed that because most of the students were young, they would not have the life experiences to allow them to fully understand what it is like to live with a chronic condition. One mentor explained: 
Patients' Messages as Educators

Doucet, Lauckner, \& Wells

Journal of Research in Interprofessional Practice and Education

Vol. 3.1

March, 2013

\section{Journal of Research in Interprofessional Practice and Education}

They've probably never had a chronic illness, they've probably never even been in a hospital, and you can't really know what it's like to be on our side of the tracks, so to speak, when you-you're twentythree and you've never had that experience.

Many of the health mentors believed that the personal perspective available to most health professional students is inadequate to understand life with a chronic condition. The health mentors felt their contribution to the education of these future healthcare practitioners was to open their eyes to the unglamorous, every day, perhaps incurable, reality of chronic disease and disability. Rather than solely understanding the disease or disability each person may be coping with, it is the impact of the condition that the health mentors emphasized was important for understanding and working with such persons. The health mentors also felt qualified and motivated to convey this message, leaving the teaching of the biological facts of health and treatment to other educators in the students' programs.

The health mentors also wanted to make the students aware that just because there may be no visible symptoms, this does not mean the patient is not suffering. One mentor described her message to the students by saying:

I divided into the more physical, debilitating part of the disease as far as visual and then the invisible symptoms that can be just as damaging or just as debilitating, and for some even more so because people can't see what is wrong.

Another mentor described a similar message: "Even though somebody walks and talks like normal, doesn't mean they are [normal]. There are so many hidden variables in anybody's life." On the other hand, the mentors also wanted the students to understand that just because someone has a chronic condition does not mean that they are always suffering. As one mentor illustrated: "It looks like you're a wreck on paper, but in real life you do things."

\section{Factors that contributed to mentors' messages being conveyed}

The mentors also identified factors that contributed to the successful conveyance of their messages. These factors included mentor characteristics and student characteristics, which spanned two themes: 1) mentor honesty and openness and 2) student questioning/listening skills.

\section{Mentor honesty and openness}

A major task of the student groups in the Dalhousie HMP is to learn about the health mentor's life history and chronic condition journey. After student groups first collaborate to develop an informal interview guide, they ask their mentor about various aspects of their life and are expected to accurately summarize the mentor's account, including those events that are particularly relevant to the mentor. These student assignments provide the opportunity for the mentors to teach the student groups what they have learned through their life journey and their interac- 
Patients' Messages as Educators

Doucet, Lauckner, \& Wells

Journal of Research in Interprofessional Practice and Education

Vol. 3.1

March, 2013

\section{Journal of Research in Interprofessional Practice and Education}

tions with the healthcare system. In order to properly convey their messages, and to give students the opportunity to really hear them, the participants identified the importance of being open and honest when sharing their stories. As one mentor recommended:

Just be willing to talk about things that perhaps you haven't talked about before, or that you don't talk about ... just be prepared to be open and honest about what your actual situation is and how it's affected your life.

Another mentor stated: “Tell the truth. [For] years I had been lying about this illness. You need to tell the truth here and be as open and honest as you can." The mentors shared the importance of being open to sharing both positive and negative messages, so that the students get the whole picture of their journey and not just the negative experiences that often stood out in their mind. The mentors' process of balancing the benefits and challenges of sharing personal experiences with students is further discussed in Lauckner, Doucet and Wells [7]. The mentors also identified the need to prepare for the meetings with the students in advance in order to be able to openly talk about their experiences. As one described: "It requires the mentor to put a lot of thought into what in their past life actually influenced their behaviors leading up to or during the period of their chronic illness."

\section{Student questioning/listening}

The health mentors also recommended that the students be more prepared to ask appropriate questions so that they could draw out the mentors' messages. Some of the mentors felt that the questions the students asked tended to draw out the bad experiences versus the good. Other mentors felt that the students were not prepared to probe for more information. As one mentor stated: "They initially had five questions and they really had no follow-up to those questions. They need to understand open and closed questions and how to follow up with comments."

The health mentors wanted the students to take a more active role in asking questions during team meetings. For example, many of the mentors felt that they did all of the talking while the students took notes. The mentors also felt that they had to encourage the students to ask questions. For instance, one mentor stated: "They don't have any skills in interviewing. They're not used to meeting someone and asking questions, especially intimate questions. You almost have to coax them along a little bit to make them feel comfortable in that technique." Many of the mentors took it on as their role to teach the students interviewing skills in order for the students to really get at their message.

\section{Discussion}

The results of our study demonstrate that patients have unique and crucial insights into the experience of chronic conditions and the practices of healthcare professionals, and that they want to use this knowledge to play an active role in educating health professional students, with the hope of improving the healthcare system. The health men- 
100

Patients' Messages as Educators

Doucet, Lauckner, \& Wells

Journal of Research in Interprofessional Practice and Education

Vol. 3.1

March, 2013 tors wanted to convey to the students the importance of interprofessional collaboration, understanding patients are people first, listening to patients, and understanding the visible and invisible impacts of living with chronic conditions. The health mentors' ability to optimally communicate their messages depended both on the mentors to openly share their experiences and on the interviewing skills of the students.

The health mentors who participated in our study were particularly keen on students learning that patients are people first. They also wanted the students to understand the unique challenges individuals with chronic conditions face and raise awareness that the impacts are both visible and invisible. The complexity of the experiences the mentors were trying to convey was evident in that they seemed to be walking a fine line of wanting the students to understand the significant impact of their condition(s), yet wanting still to be seen as a person.

The health mentors' messages around the need for improved interprofessional collaboration and teamwork in healthcare validate having interprofessional student teams participate in this initiative. Moreover, the mentors' conviction that students need to understand firsthand the impact of chronic conditions supports having patient educators participate, as they are truly the experts in sharing their experiences. As in research by Stacy and Spencer [8], the patient educators in our study felt that they had the expertise to make specific contributions to student learning.

An additional central message was for health professionals to be better communicators, in particular, active listeners. Similarly, Jackson and colleagues [9] identified listening as a key message that patient educators hoped to instill in their students, as they viewed listening as fundamental to accessing the expertise of patients. Interestingly, in our research, many of the mentors identified that the students' novice communication skills acted as barriers to mentors being able to convey their messages. While the mentors entered the program thinking they would easily share their messages through telling their stories, many of the mentors informally coached students on their communications skills so the students could learn about the mentors' experiences (e.g., mentors encouraged the students to probe). Previous research has shown that interactions with patient educators can improve students' communication skills [10], and it is possible that such coaching by patient educators to truly listen to their messages is a mechanism through which these skills are developed.

The mentors' perception that students had novice communication skills supports the need for improved student preparation in basic interviewing skills prior to participating in such a program. For the most part, the students participating in the Dalhousie HMP were in the first year of their professional program. In HMPs and other similar programs, it is important to ensure that students have opportunities to learn effective basic communication skills early in their professional training so that they can fully benefit from such a program. This basic student preparation is also essential out of respect for the patient educators who are volunteering their time. While further investigation is required to determine the optimal level of the students to participate in this type of program, this research and the previous work by Jackson et al. [9] indicates that patient educators want to meet with students early 
101

Patients' Messages as Educators

Doucet, Lauckner, \& Wells

Journal of Research in Interprofessional Practice and Education

Vol. 3.1

March, 2013 in their training so that they can make a lasting impact before bad practices and stereotypes are established. Students also report that they prefer to learn from patients in this type of context early in their training, as it provides real-life context to their learning and a better understanding of the patient experience [10].

The mentors also identified that they themselves needed to prepare for the interviews to be able to optimally communicate their message with the students. Some of the mentors felt unprepared to answer the students' questions and wished they had a better understanding of the types of questions that would be asked so that they could think these through in advance. Research involving students engaged in a similar interprofessional initiative further supports the need for patient educator preparation, as students identified patient educators' memory of events as a barrier to their learning [2]. In future research, it will be important to determine the appropriate level of training and preparation for patient educators involved in interprofessional teaching.

Although we are in the planning stages of evaluating the impact of the Dalhousie HMP from the students' perspectives, anecdotal feedback suggests there is congruence with the messages the students received and the messages the mentors were aiming to deliver. In future research, it would be valuable to include the patient educators and students in the same study to evaluate whether the students indeed hear the messages the patient educators are intending to deliver. Research is also needed to explore the actual impact of such programs on learning from the students' perspective and the short- and long-term effects on professional practice.

There are limitations to this study. First, the 30 health mentors who participated in our study may not be representative of the other 151 health mentors who participated in the Dalhousie HMP. However, given that we achieved data saturation with the first 30 participants who volunteered to participate, we are confident that the findings are transferable to the other mentors. Second, the messages the mentors hoped to convey may be a reflection of the objectives of the Dalhousie HMP, which are for the students to learn about patient/client-centred practice, team functioning, and chronic conditions and disabilities. However, it is also possible that the mentors participated in the Dalhousie HMP because it was the perfect avenue to be able to share their personal messages with health professional students. Finally, there is the possibility that the transferability of findings may be limited to similar interprofessional initiatives with a focus on chronic conditions/disabilities and may not transfer to uniprofessional initiatives or acute-care focused programs that involve patient educators.

It is evident from our research that patients clearly want to play an active role in health professional education and that they have important messages they want to share with students. There are a number of factors driving the increase in involvement of patients in the education of health professionals, including changes in healthcare delivery to become more patient-centred. If we expect our students to become competent in providing interprofessional, patient-centred care, we need to incorporate patient-centred interprofessional learning opportunities early on and throughout students' training to optimally inform their practice. It is important that 


\section{JRIPE}

102

Patients' Messages

as Educators

Doucet, Lauckner, \& Wells

we are aware of the messages patients are hoping to convey so that we can help reinforce and genuinely honour their messages with our students. This will ensure that such interprofessional initiatives embody the principle of patient-centredness that we aim to instill in our students.

\section{Abbreviations}

HMP = Health Mentors Program

$\mathrm{SD}=$ Standard Deviation

\section{References}

1. Spencer, J., Blackmore, D., Heard, S., McCrorie, P., McHaffie, D., Scherpbier, A., Gupta, T.S., Singh, K., \& Southgate, L. (2000). Patient-oriented learning: A review of the role of the patient in the education of medical students. Medical Education, 34, 851-857.

2. Solomon, P. (2011). Student perspectives on patient educators as facilitators of interprofessional education. Medical Teacher, 33(10), 851-853.

3. Collins, L., Arenson, C., Jerpbak, C., Kane, P., Dressel, R., \& Antony, R. (2011). Transforming chronic illness care education: A longitudinal interprofessional mentorship curriculum. Journal of Interprofessional Care, 25(3), 228-230.

4. Towle, A., Bainbridge, L., Godolphin, W., Katz, A., Kline, C., Lown, B., Madularu, I., Solomon, P., \& Thistlethwaite, J. (2010). Active patient involvement in the education of health professionals. Medical Education, 44, 64-74.

5. Polit, D.F., \& Beck, C.T. (2004). Nursing research. Principles and methods, $7^{\text {th }}$ edition. Philadelphia, PA: Lippincott Williams and Wilkins.

6. Braun, V., \& Clarke, V. (2006). Using thematic analysis in psychology. Qualitative Research in Psychology, 3, 77-101.

7. Lauckner, H., Doucet, S., \& Wells, S. (2012). Patient educators' experiences: Balancing the risks and benefits of sharing personal information with students. Medical Education, 46, 992-1000.

8. Stacy, R., \& Spencer, J. (1999). Patients as teachers: A qualitative study of patients' viewson their role in a community-based undergraduate project. Medical Education, 33, 688-694.

9. Jackson, A., Blaxter, L., \& Lewando-Hundt, G. (2003). Participating in medical education: Views of patients and carers living in deprived communities. Medical Education, 37, 532-538.

9. Wykurz, G., \& Kelly, D. (2002). Developing the role of patients as teachers: Literature review. British Medical Journal, 325, 818-821.

10. Muir, F. (2007). Placing the patient at the core of teaching. Medical Teacher, 29, 258-260. 